\title{
Realization of Single-phase White-Light-Emitting Materials with Time-Evolution Ultralong Room Temperature Phosphorescence by Coordination Assemblies
}

Hui Liu, ${ }^{1,2}$ Kun Zhang,,${ }^{1,2}$ Peng-Fu Gao,,${ }^{1,3}$ Jia-Hua Luo, ${ }^{1}$ Yu-Ying Jiang,,${ }^{1,2}$ Meng-Shu Zhou, ${ }^{1,3}$ Ting Li, ${ }^{1}$ Xue-Li Zhu, ${ }^{1}$ Hong-Ru Fu,,${ }^{1,2}$

${ }^{1}$ College of Chemistry and Chemical Engineering, Luoyang Normal University, Luoyang 471934, China. E-mail: hongrufu2015@163.com.

${ }^{2}$ College of Materials and Chemical Engineering, China Three Gorges University, Yichang 443002 China

${ }^{3}$ College of Chemistry and Chemical Engineering, Henan Polytechnic University, Jiaozuo 454003, China 


\section{EXPERIMENTAL SECTION}

\section{Materials and Methods.}

5-(carbazol-9-yl) isophthalate (CzIP) was synthesized by the following published method. [1] Powder X-ray diffraction (PXRD) patterns were acquired on a Bruker D8 ADVANCE diffractometer with $\mathrm{Cu} \mathrm{K \alpha}(\lambda=1.5418 \AA)$ radiation in the range of $\theta=5-50^{\circ}$ at room temperature. Thermogravimetric analysis (TGA) was performed on a PerkinElmer TG-7 analyzer heated from room temperature to $800{ }^{\circ} \mathrm{C}$ at a ramp rate of $5{ }^{\circ} \mathrm{C} / \mathrm{min}$ under a nitrogen gas atmosphere. Elemental analyses (C, H, and N) were conducted on a PerkinElmer $240 \mathrm{C}$ elemental analyzer. Ultraviolet-visible (UV-vis) absorption spectra were collected on a PerkinElmer Lambda 35 spectrophotometer. The fluorescence and temperature-dependent phosphorescence spectra were performed on FLS1000 Edinburgh photoluminescence spectrometer. The quantum yields were measured on FLS1000 also, and luminescence lifetimes were obtained on a single photon counting spectrometer with micro-second pulse lamp.

\section{Ligand Synthesis}

\section{Fisrtly, the synthesis of carbazole.}

According to the previous literature, the tiny amounts of isomeric impurities can affect the phosphorescence behaviors, so the carbazole sample was prepared. [2] In addition, the carbazole sample was obtained from commercial sources was purified and compared with the synthesis.

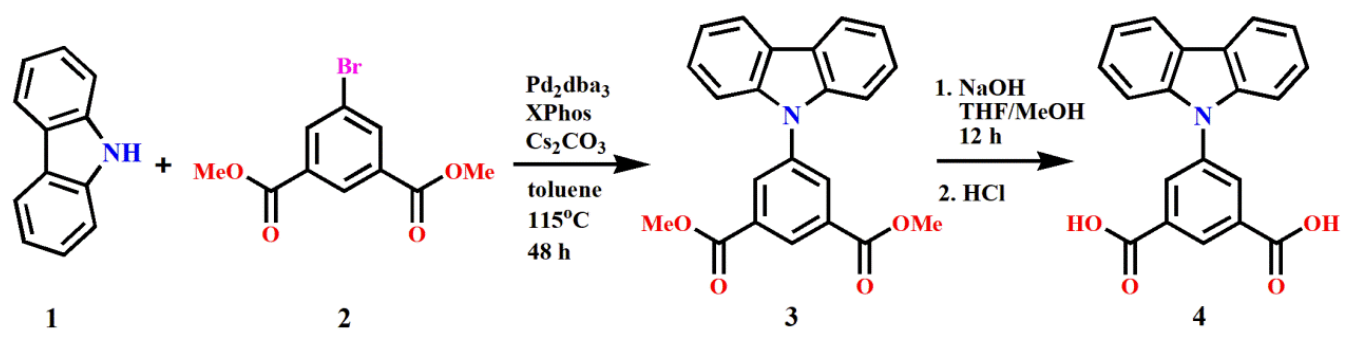

Scheme S1. The synthesis of CzIP.

\section{The synthesis of dimethyl 5-(9H-carbazol-9-yl)-isophthalate (3)}

Carbazole 1 (2.50 g, $15.0 \mathrm{mmol})$ was mixed with dimethyl 5-bromoisophthalate 2 (6.33 g, 12.00 mmol), dipalladium(0) trisdibenzylideneacetone $\left(\mathrm{Pd}_{2} \mathrm{dba}_{3}\right)(0.32 \mathrm{~g}, 0.38 \mathrm{mmol}), \mathrm{Cs}_{2} \mathrm{CO}_{3}(9.78 \mathrm{~g}$, $30.00 \mathrm{mmol}$ ) and 2-dicyclohexylphosphino-2',4',6'-triisopropylphenyl (XPhos) (0.05 g, 0.10 mmol) in toluene $(120 \mathrm{~mL})$. The round bottom flask was evacuated and refilled with nitrogen, 
then maintained $115^{\circ} \mathrm{C}$ and refluxed 48 hours. Reaction was quenched with saturated aqueous solution of EDTA and $\mathrm{NaHCO}_{3}(80 \mathrm{~mL})$, extracted with EtOAc $(4 \times 100 \mathrm{~mL})$, washed with deionized $\mathrm{H}_{2} \mathrm{O}$, dried with anhydrous $\mathrm{MgSO}_{4}$, filtered. Solvent was removed under reduced pressure. Gradient column was found to be the most effective way of separation: starting from solvents mixture as eluent (dichloromethane:hexane, $\mathrm{v}: \mathrm{v}=1: 3$ ) to pure. Dimethyl 5-(9H-carbazol-9-yl)-isophthalate 3 was obtained as a white solid (3.0 g, $70 \%$ yield base on 2). in order to further improve the purification, 5-(9H-carbazol-9-yl)-isophthalate power was recrystallized from ethanol solution.

\section{The synthesis of 5-(9H-carbazol-9-yl)-isophthalic acid (4)}

Dimethyl 5-(9H-carbazol-9-yl)-isophthalate $3(3.00 \mathrm{~g}, 8.30 \mathrm{mmol})$ was dissolved in THF (120 $\mathrm{mL})$ and $\mathrm{MeOH}(80 \mathrm{~mL})$ was added. After that $\mathrm{NaOH}$ aqueous $(80 \mathrm{~mL}, 4 \mathrm{~mol} / \mathrm{L})$ was added. Reaction mixture was heated to $60^{\circ} \mathrm{C}$ and kept at that temperature. Reaction completion was monitored by TLC, which showed full conversion after 12 hours. After that reaction mixture was cooled down and organic solvents were removed under reduced pressure. Aqueous layer was acidified with $\mathrm{HCl}(4 \mathrm{~mol} / \mathrm{L})$ until white precipitate occurred. Precipitate was washed with deionized $\mathrm{H} 2 \mathrm{O}$ and dried under high vacuum. 5-(9Hcarbazol-9-yl)-isophthalic acid 4 was obtained as a white solid ( $2.40 \mathrm{~g}, 92 \%$ yield).

\section{Synthesis of Compounds 1 and 2}

\section{Synthesis of 1}

A mixture of 5-(9H-Carbazol-9-yl)-1,3-benzenedicarboxylic acid (CzIP, $15 \mathrm{mg}, 0.045 \mathrm{mmol})$, (S)-mandelate $(15 \mathrm{mg}, 0.10 \mathrm{mmol})$ and $\mathrm{CdSO}_{4} \cdot 4 \mathrm{H}_{2} \mathrm{O}(50 \mathrm{mg}, 0.2 \mathrm{mmol})$ was added in a $20 \mathrm{~mL}$ glass vial; subsequently, $\mathrm{H}_{2} \mathrm{O} / \mathrm{DEF}(10 \mathrm{~mL}, \mathrm{v} / \mathrm{v}=8 / 2)$ solvent was added to the solids. The vial was heated in a programmable oven at $150{ }^{\circ} \mathrm{C}$ for $72 \mathrm{~h}$, the colorless transparent needle-like crystals were obtained. Cooled naturally to room temperature, and then washed with DMF for three times (yield: 63\%). Anal. Calcd for $\mathrm{C}_{70} \mathrm{H}_{61} \mathrm{Cd}_{3} \mathrm{~N}_{5} \mathrm{O}_{17}(\%)$ : C, 53.13; H, 3.74; N, 4.43; Found: C, 52.90; H, 3.78; N, 4.45 .

\section{Synthesis of 2}

A mixture of 5-(9H-Carbazol-9-yl)-1,3-benzenedicarboxylic acid (CzIP, $20 \mathrm{mg}, 0.06 \mathrm{mmol}$ ), (L)-1-(1H-Benzimidazol-2-yl)ethylamine Hydrochloride (L-BIM, $15 \mathrm{mg}, 0.10 \mathrm{mmol}$ ) and 
$\mathrm{Cd}(\mathrm{OAC})_{2} \cdot 2 \mathrm{H}_{2} \mathrm{O}(40 \mathrm{mg}, 0.17 \mathrm{mmol})$ was added in a $20 \mathrm{~mL}$ glass vial; subsequently, $5 \mathrm{~mL}$ of N,N-Dimethylformamide (DMF) solvent was added to the solids. The vial was heated in a programmable oven at $120{ }^{\circ} \mathrm{C}$ for $48 \mathrm{~h}$, the light yellow block crystals were obtained. Cooled naturally to room temperature, and then washed with DMF for three times (yield: 57\%). Anal. Calcd for $\mathrm{C}_{51} \mathrm{H}_{46} \mathrm{Cd}_{2} \mathrm{~N}_{6} \mathrm{O}_{11}(\%)$ : C, 53.51; H, 4.02; N, 7.34; Found: C, 52.90; H, 3.88; N, 7.45.

\section{LED devices}

The light-emitting diodes (LEDs) used for the white electroluminescence were supplied by Shenzhen Chundaxin Optoelectronic Corp. The LED die is mounted in a metal can and is contacted by gold wire bonds. Sample powders were firstly solved in ethanol, and then stirred for $10 \mathrm{~min}$. After deaeration in vacuum oven at room temperature, the mixture was deposited on top of the LED chip. They consist of a fully packaged Epileds InGaN LED Chips with an emission wavelength of about $360 \mathrm{~nm}$. The forward current of the LEDs is $350 \mathrm{~mA}$. Electroluminescence (EL) measurements of the LEDs were carried out at room temperature using an Everfine HAAS-2000. For the light collection the LEDs were placed inside a $30 \mathrm{~cm}$ diameter integrating sphere coupled to a High Accuracy Array Spectroradiometer (wavelength accuracy $<0.3 \mathrm{~nm}$ ) and a programmable test power LED300E.

\section{Quantum yields calculation}

The quantum yields (QYs) performed on FLS1000 Edinburgh photoluminescence spectrometer (under the optimal excitation wavelengths based on the spectra measurement). The phosphorescence QYs was calculated using the following equation by reference to the literatures.[3,4] As follows:

$$
\Phi_{\text {Phos }}=\Phi_{P L} * \frac{A_{\text {Phos }}}{A_{F L}+A_{\text {Phos }}}
$$

Herein, $\Phi_{\mathrm{Phos}}$ is the phosphorescence $\mathrm{QY}, \Phi_{\mathrm{PL}}$ is the PL QY; $\mathrm{A}_{\mathrm{FL}}$ and $\mathrm{A}_{\mathrm{Phos}}$ are integral peak areas of fluorescence FL and phosphorescence.

\section{Computational methods}

TD-DFT calculations were performed on Gaussian 09W program. The initial geometries were 
obtained from the single crystal structures. Molecular geometry optimizations of monomer and dimers were performed for energy orbit. On the basis of structural optimization, TD-DFT was conducted to calculate the exciton energies in singlet and triplet states.

a)

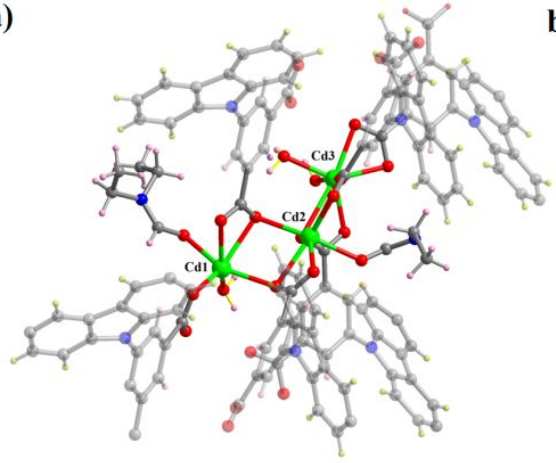

b)

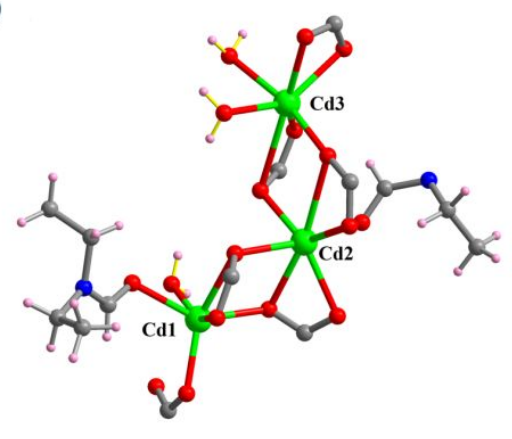

c)

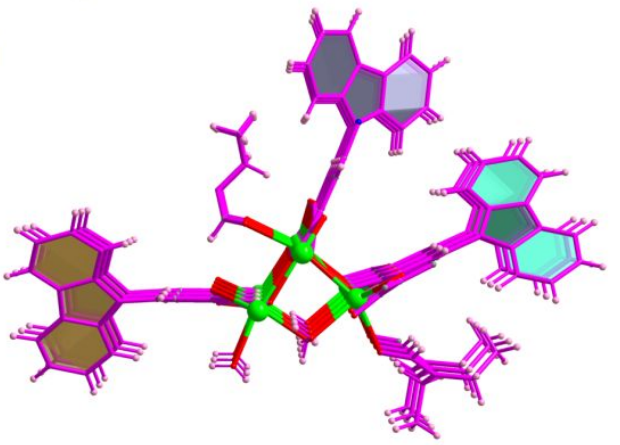

d)

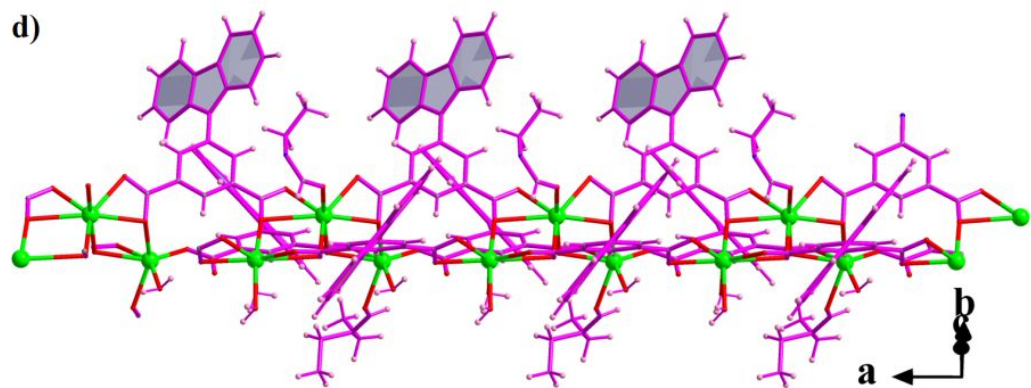

Figure S1. a) Three crystallographically independent $\mathrm{Cd}^{2+}$ ions in compound 1; b) The $\mathrm{Cd} 1$ center exhibits the disordered $\left[\mathrm{ZnO}_{6}\right]$ octahedral coordination geometry, four oxygen atoms from three carboxylate groups of three ligands, the others from three terminal DMF molecule and water molecule. $\mathrm{Cd} 2$ is seven-coordinated by seven oxygen atoms, six oxygen atoms from four carboxylate groups of four ligands, one from the terminal DMF molecules, while the $\mathrm{Cd} 3$ presents the double pentagonal pyramid configuration, coordinated by seven oxygen atoms from five oxygen atoms from three carboxylate groups of three ligands and two terminal water molecules; c) the $1 \mathrm{D}$ chain consists of $\mathrm{CzIP}$ and $\mathrm{Cd}^{2+}$ ions; d) the 1D chain in the direction of $\mathrm{c}$ axis. 


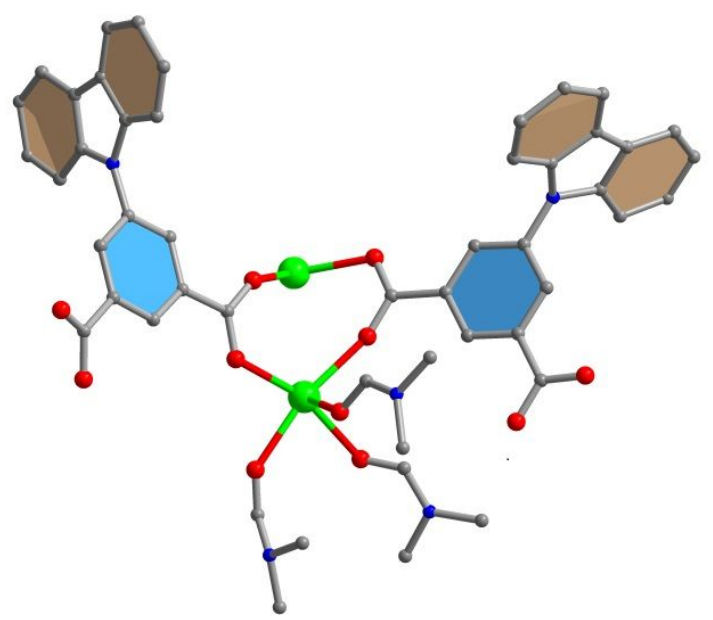

Figure S2. Coordination environment of compound 2.

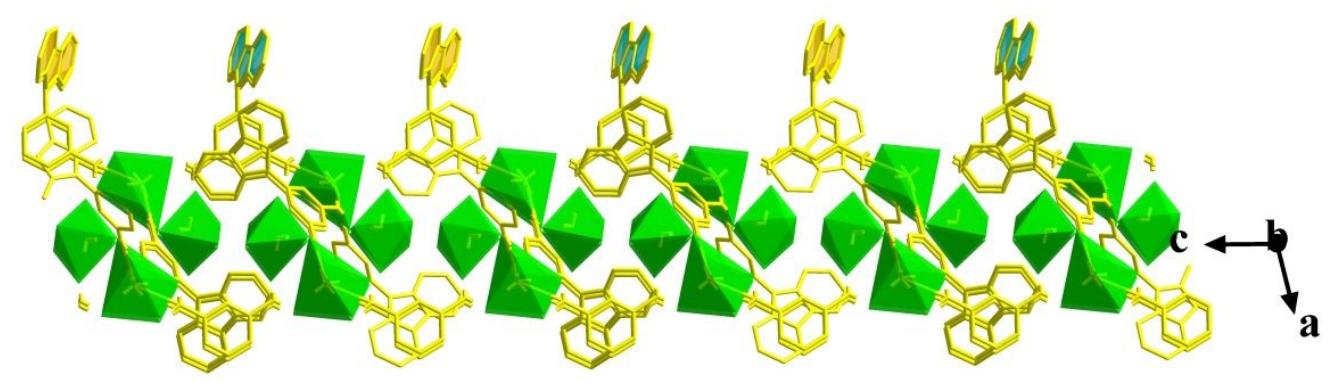

Figure S3. 1D chain assemblies of CzIP and metal nodes in compound 2 long the $\mathrm{b}$ axis.

a)
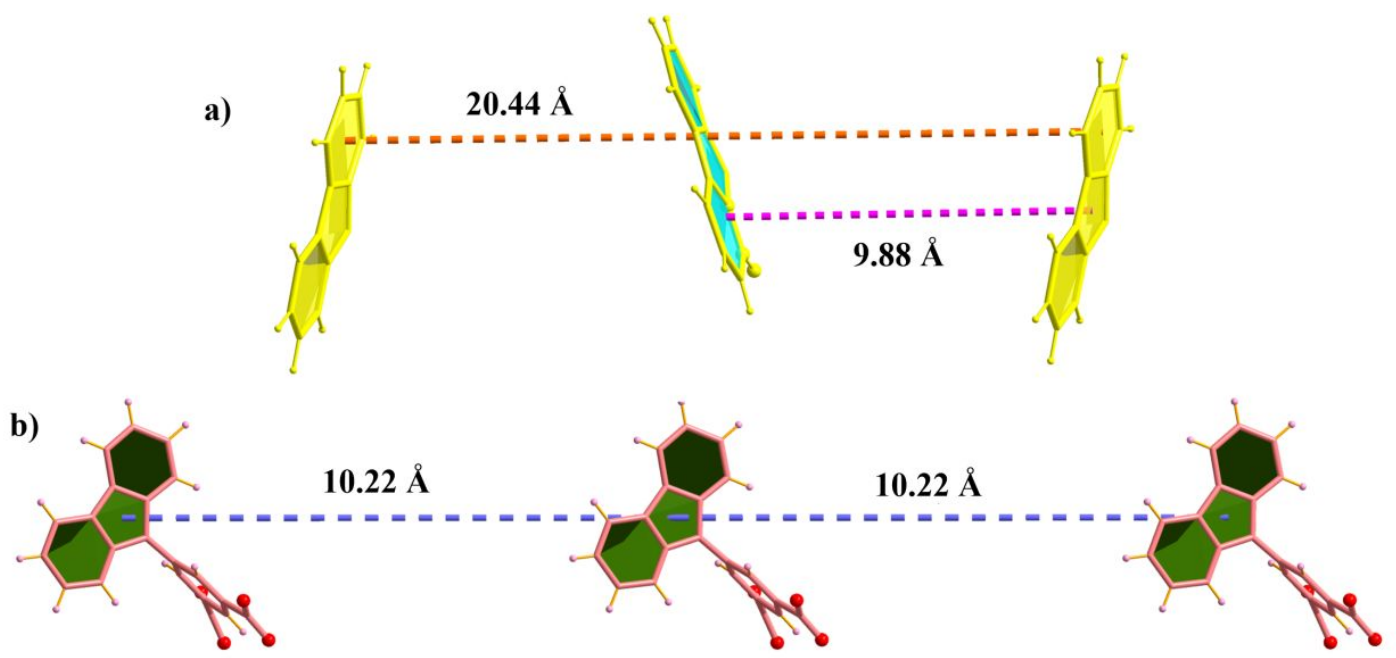

Figure S4. (a) The distance of carbazole skeleton in the crossed double chain; (b) the distance of carbazole skeleton in the same direction. 


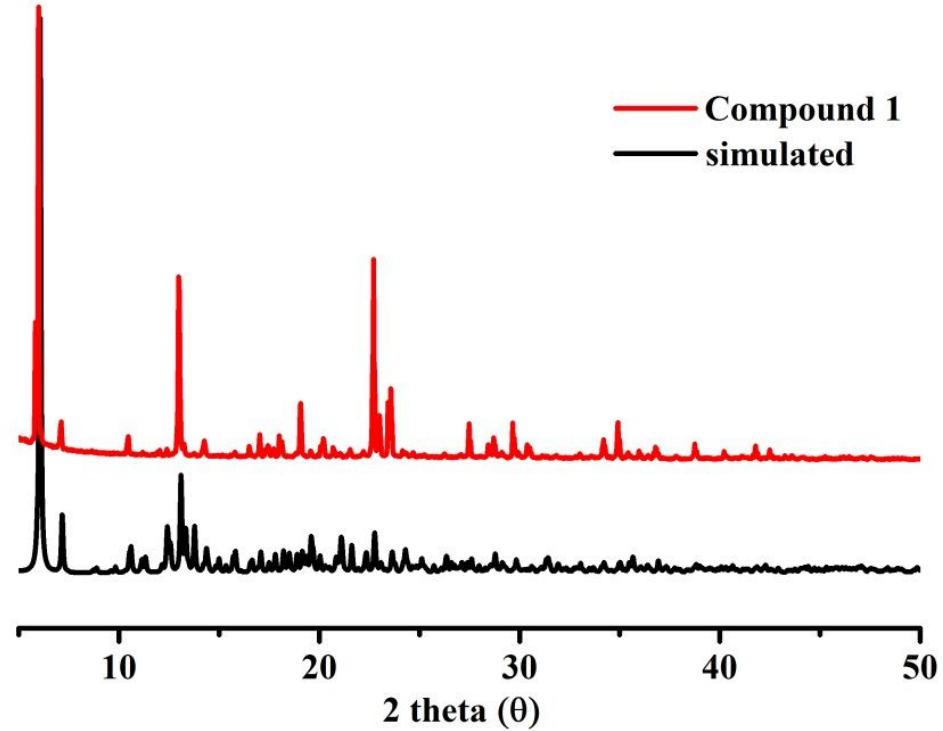

Figure S5. XRD patterns of the compound 1 .

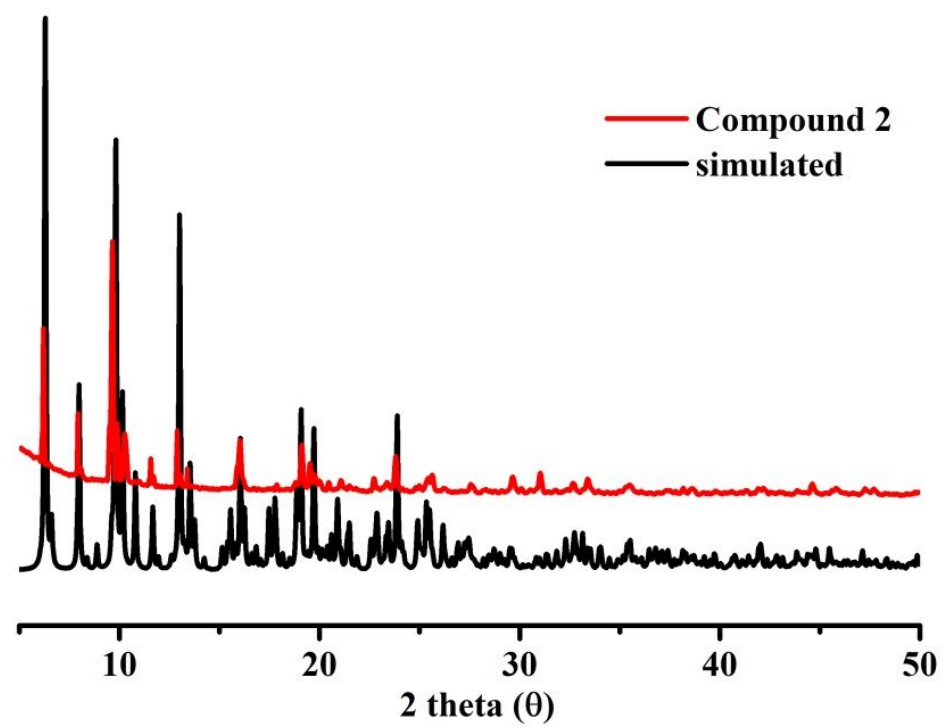

Figure S6. XRD patterns of the compound 2. 


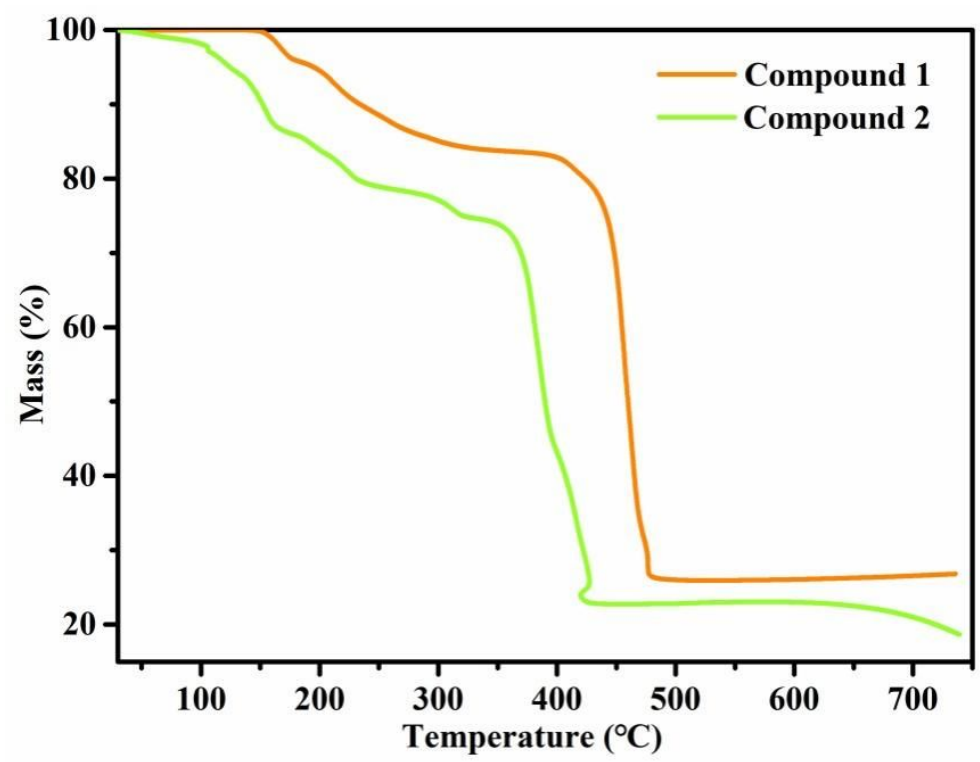

Figure S7. TGA curves of compounds 1 and $\mathbf{2}$ under air atmosphere.

\begin{tabular}{|l|l|l|}
\hline \multicolumn{3}{|c|}{ Table S1 Torsion angle between carbazole $(\mathrm{Cz})$ and benzene $\operatorname{ring}(\mathrm{BR})$ of compound $\mathbf{1}$ and $\mathbf{2}}$. \\
\hline \multirow{4}{*}{ compound 1 } & torsion angle between $\mathrm{Cz}$ and $\mathrm{BR} /{ }^{\circ}$ \\
\cline { 2 - 3 } & purple bond and orange fill & 49.6 \\
\cline { 2 - 3 } & purple bond and green fill & 41.2 \\
\cline { 2 - 3 } & yellow bond and yellow fill & 40.7 \\
\cline { 2 - 3 } & red bond and red fill & 39.5 \\
\cline { 2 - 3 } & green bond and green fill & 40.3 \\
\hline \multirow{3}{*}{ compound 2 } & yellow bond and yellow fill & 79.3 \\
\cline { 2 - 3 } & yellow bond and blue fill & 77.7 \\
\cline { 2 - 3 } & brown bond and deep green fill & 76.8 \\
\hline
\end{tabular}

Notice: The Type of the carbazole monomer was defined on the band color and the fill color, which was drawn in the figure in manuscript. 


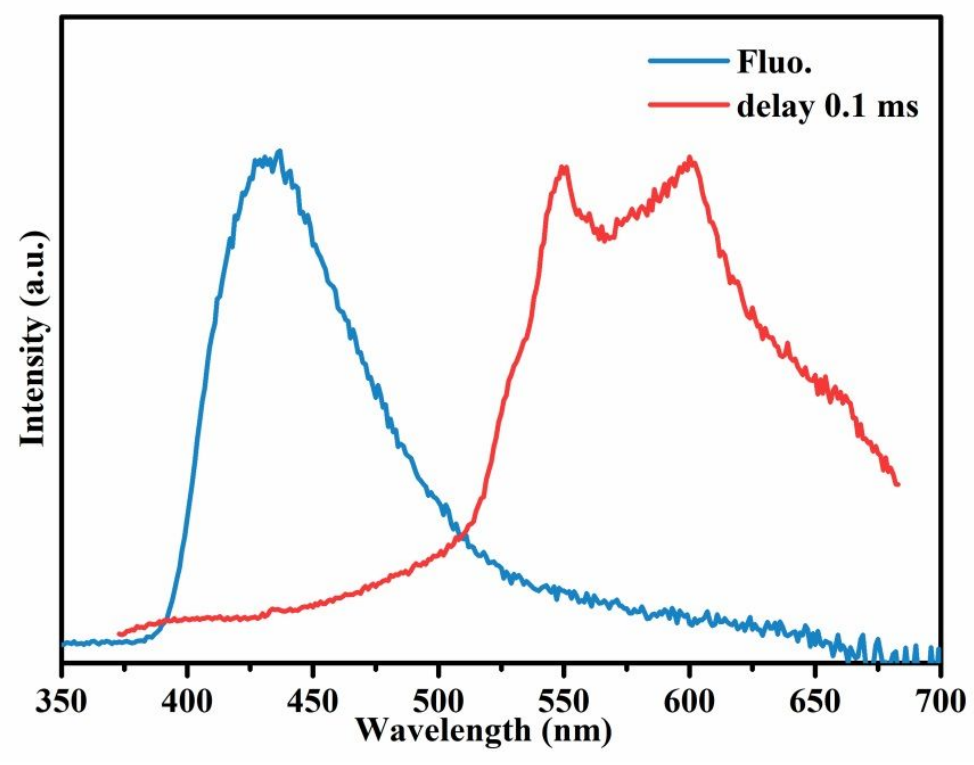

Figure S8. Prompt and delayed PL emission spectra of CzIP.

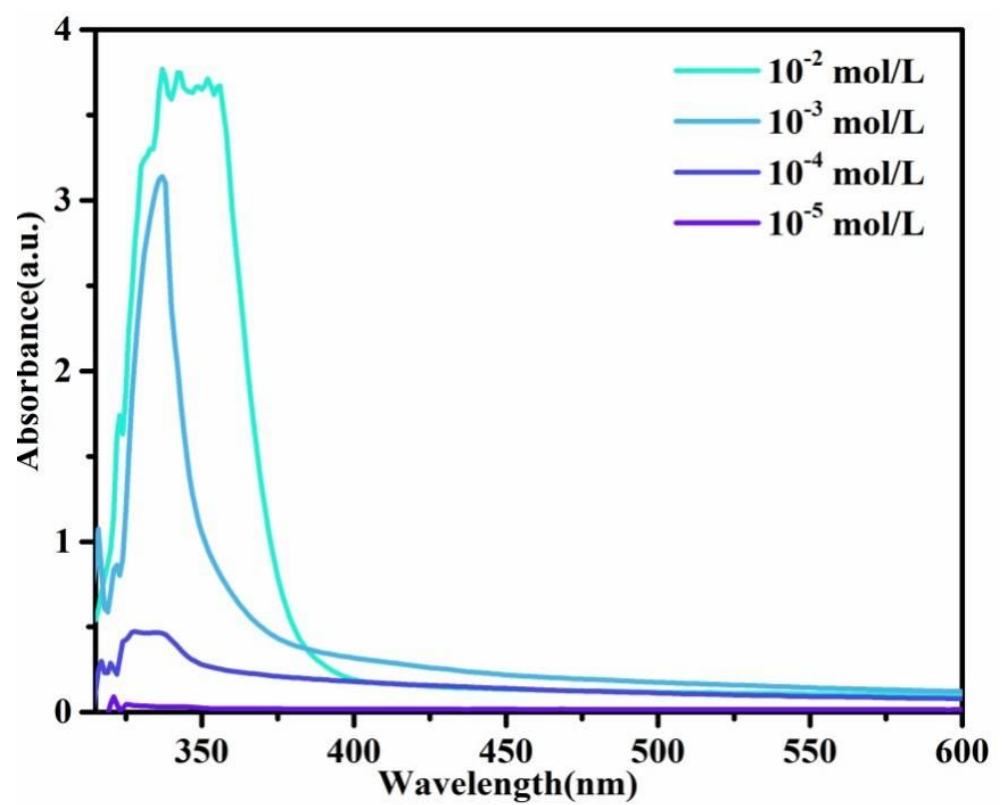

Figure S9. Adsorption of CzIP in acetone solution from $10^{-5}$ to $10^{-2} \mathrm{~mol} / \mathrm{L}$. 


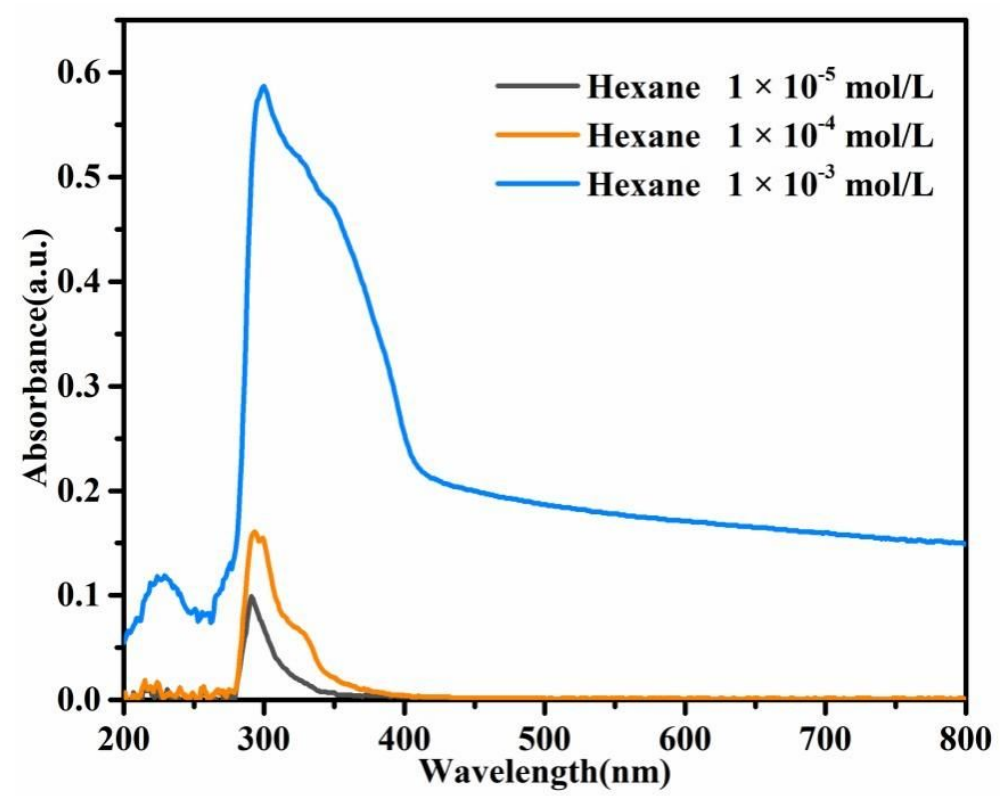

Figure S10. Adsorption of CzIP in hexane solution from $10^{-5}$ to $10^{-3} \mathrm{~mol} / \mathrm{L}$.

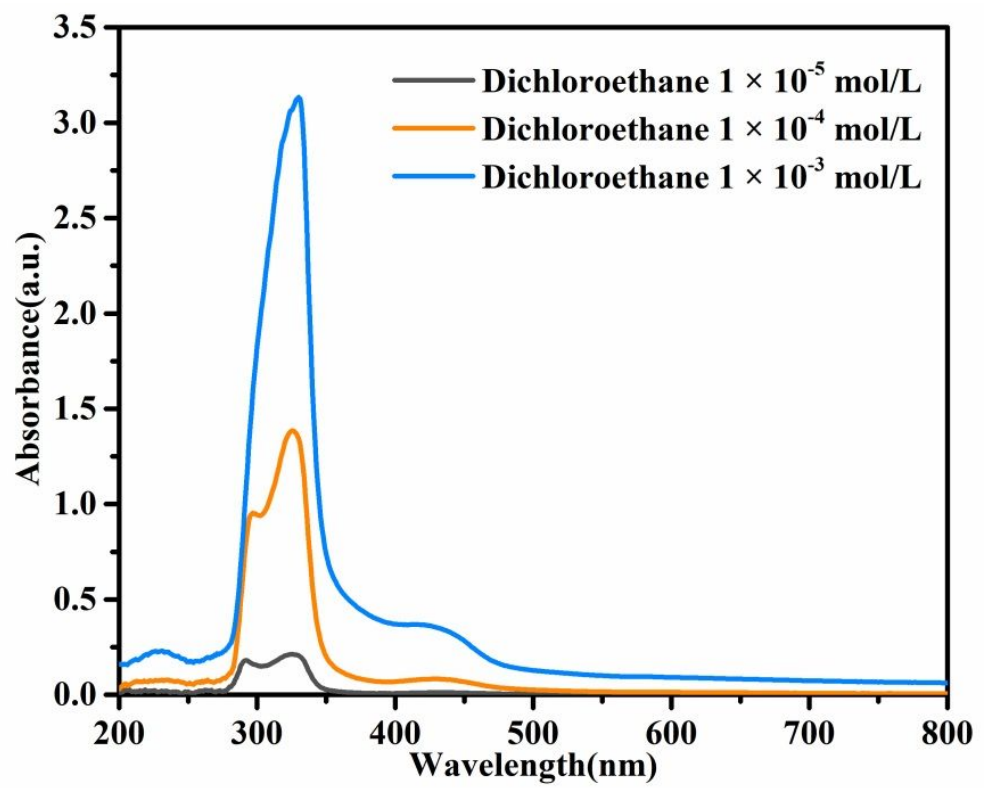

Figure S11. Adsorption of CzIP in dichloroethane solution from $10^{-5}$ to $10^{-3} \mathrm{~mol} / \mathrm{L}$. 


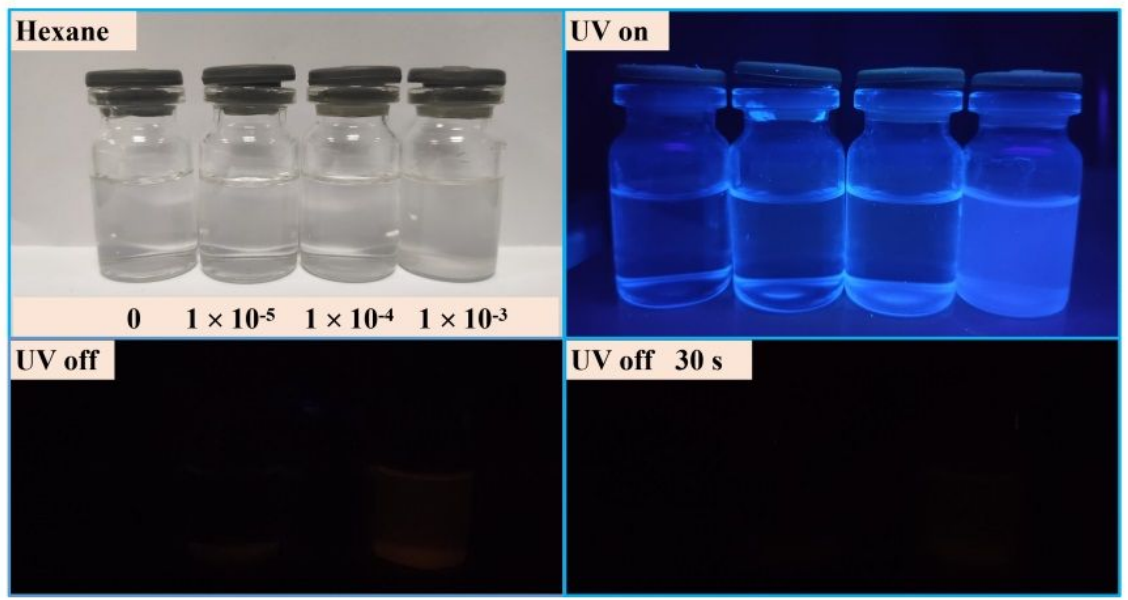

Figure S12. Luminescence of hexane solution with gradient concentrations $\left(0,1 \times 10^{-5} \mathrm{M}, 1 \times 10^{-4}\right.$ $\mathrm{M}, 1 \times 10^{-3} \mathrm{M}$ ) CzIP in daylight, under $365 \mathrm{~nm}$ UV lamp and after turning off UV lamp

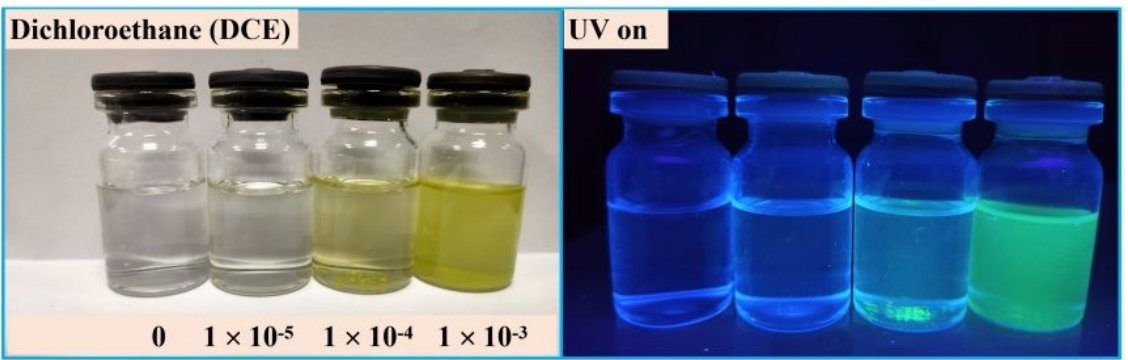

Figure S13. Luminescence of $\mathrm{CH}_{3} \mathrm{CHCl}_{2}$ solution with gradient concentrations $\left(0,1 \times 10^{-5} \mathrm{M}\right.$, $\left.1 \times 10^{-4} \mathrm{M}, 1 \times 10^{-3} \mathrm{M}\right) \mathrm{CzIP}$ in daylight, under $365 \mathrm{~nm}$ UV lamp.

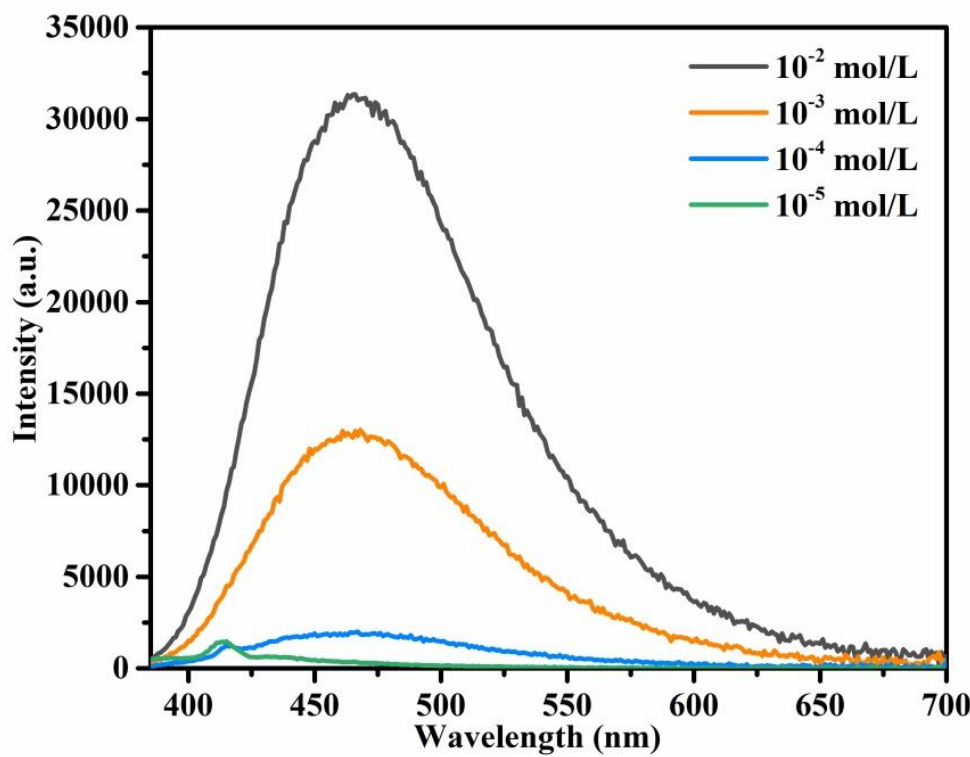

Figure S14. Fluorescence spectrum of CzIP in acetone solution from $10^{-5}$ to $10^{-3} \mathrm{~mol} / \mathrm{L}$. 


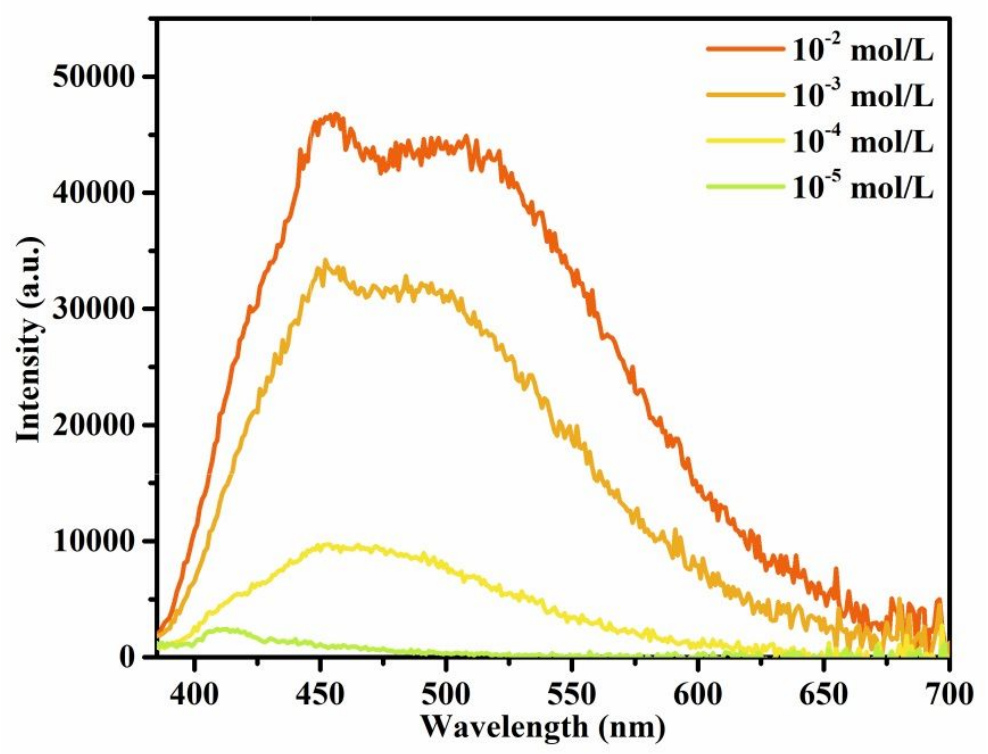

Figure S15. Phosphorescent spectrum of CzIP in acetone solution from $10^{-5}$ to $10^{-3} \mathrm{~mol} / \mathrm{L}$.

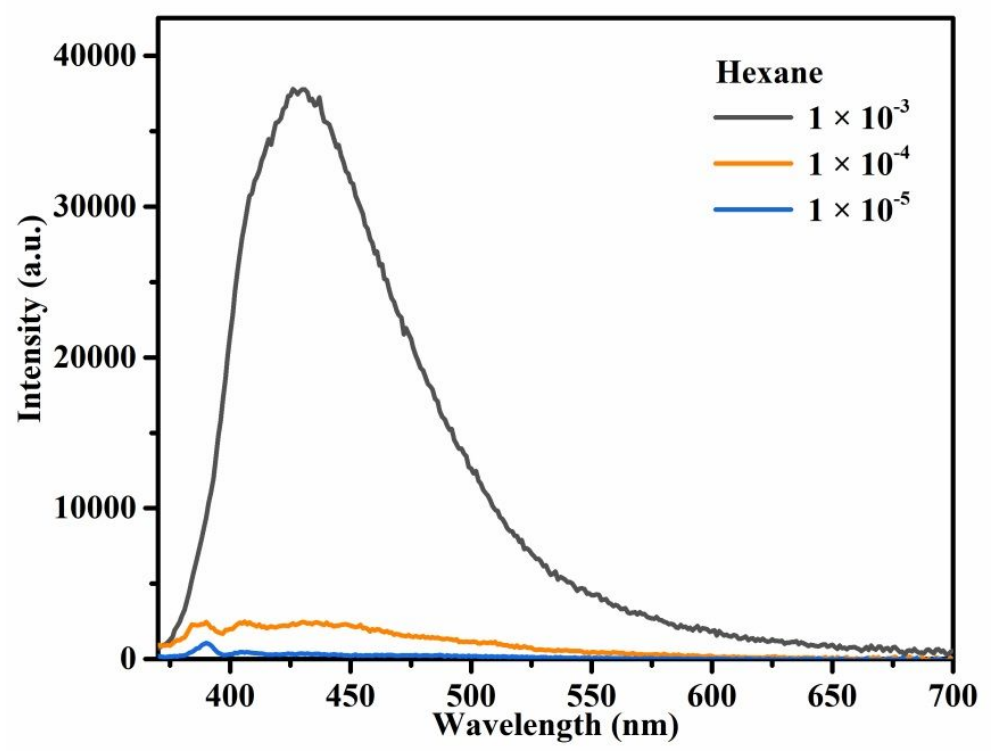

Figure S16. Fluorescence spectrum of CzIP in Hexane solution from $10^{-5}$ to $10^{-3} \mathrm{~mol} / \mathrm{L}$. 


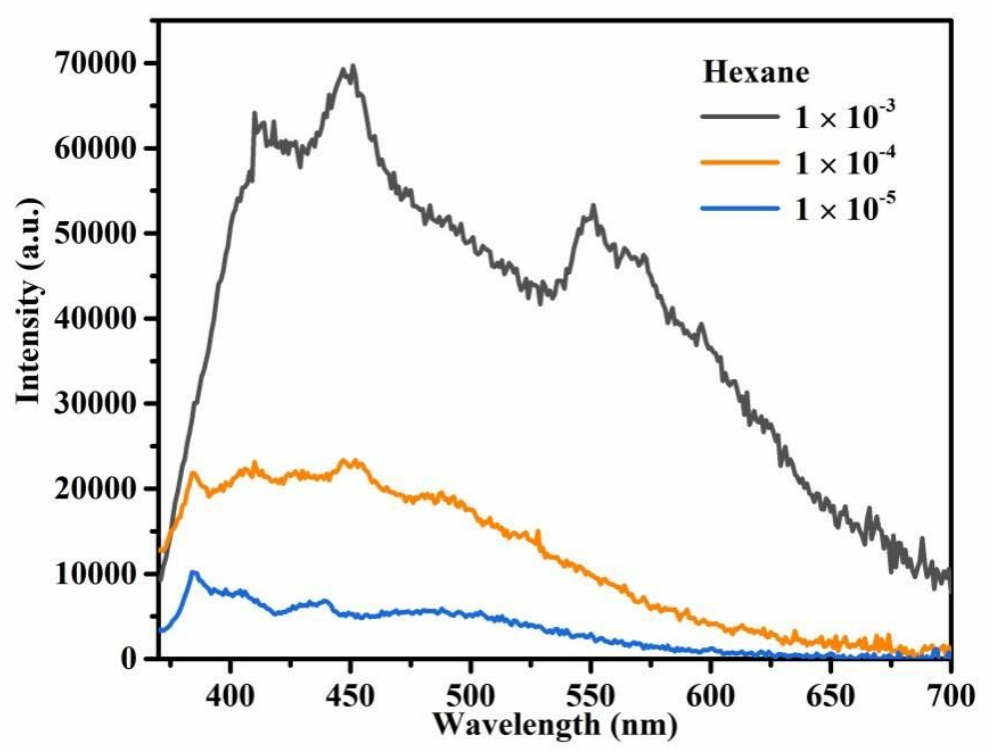

Figure S17. Phosphorescent spectrum of CzIP in Hexane solution from $10^{-5}$ to $10^{-3} \mathrm{M}$.

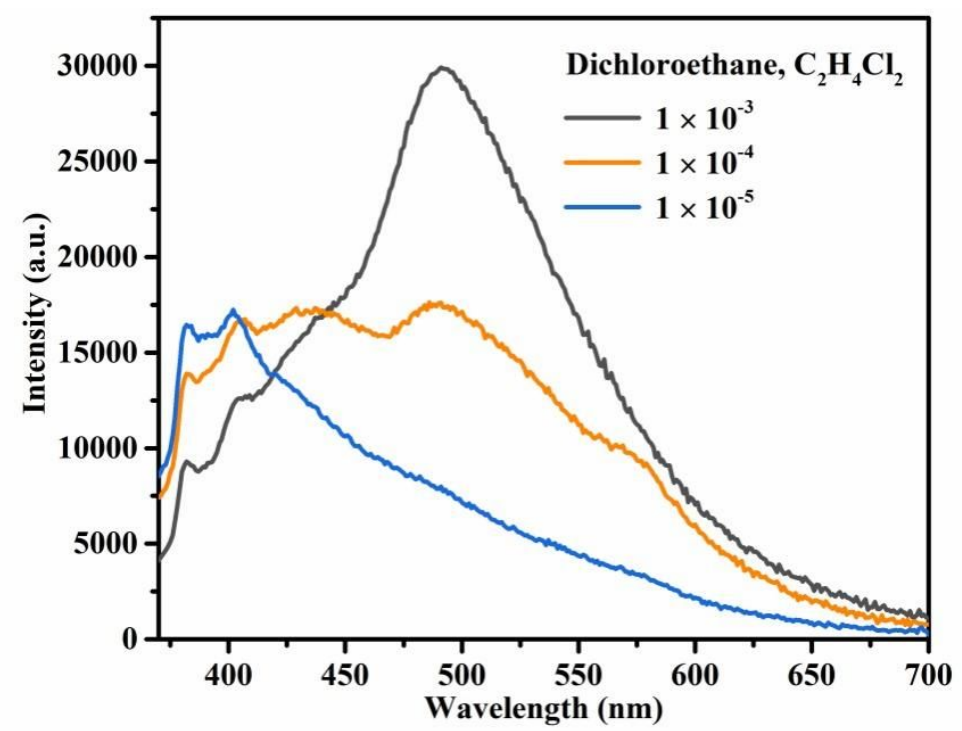

Figure S18. Fluorescence spectrum of CzIP in $\mathrm{C}_{2} \mathrm{H}_{4} \mathrm{Cl}_{2}$ solution from $10^{-5}$ to $10^{-3} \mathrm{~mol} / \mathrm{L}$. 


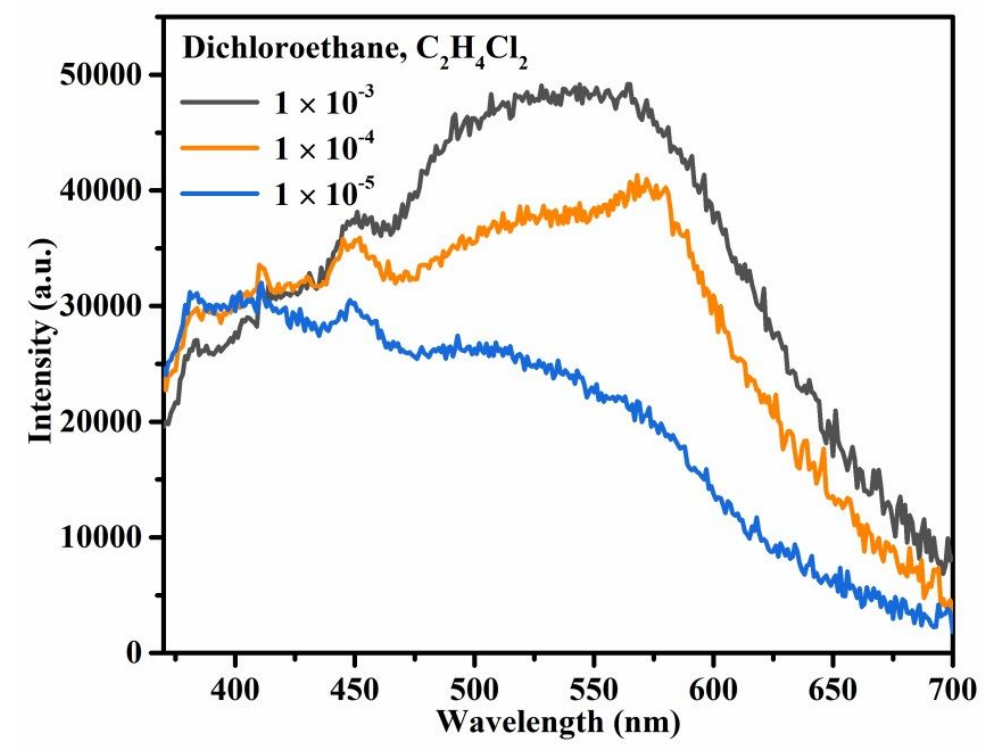

Figure S19. Phosphorescent spectrum of CzIP in $\mathrm{C}_{2} \mathrm{H}_{4} \mathrm{Cl}_{2}$ solution from $10^{-5}$ to $10^{-3} \mathrm{~mol} / \mathrm{L}$.

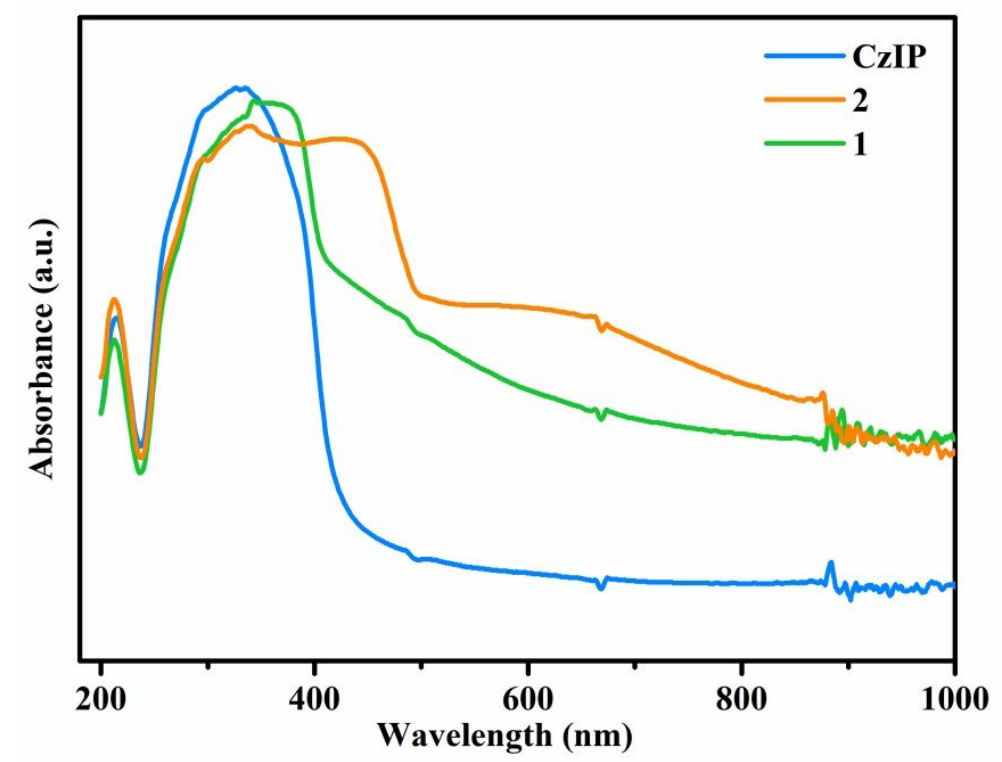

Figure S20. Solid state UV-vis absorbance of CzIP powder, compounds 1 and $\mathbf{2}$ crystal samples at ambient condition. 


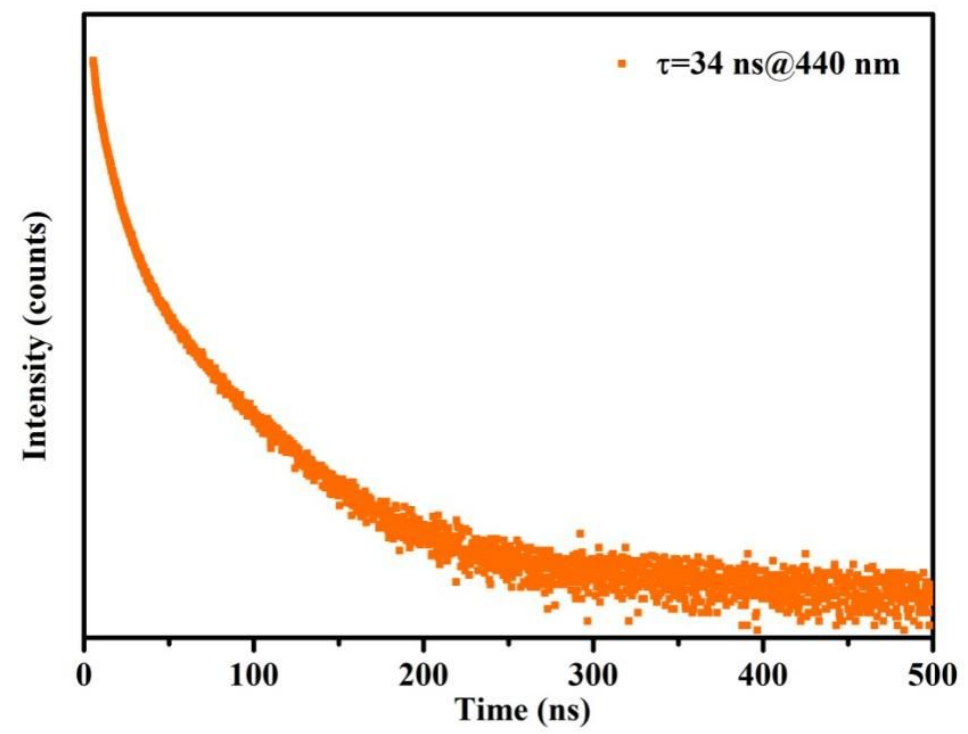

Figure S21. The lifetime of the fast decay at $440 \mathrm{~nm}$ of crystal sample $\mathbf{1}$.

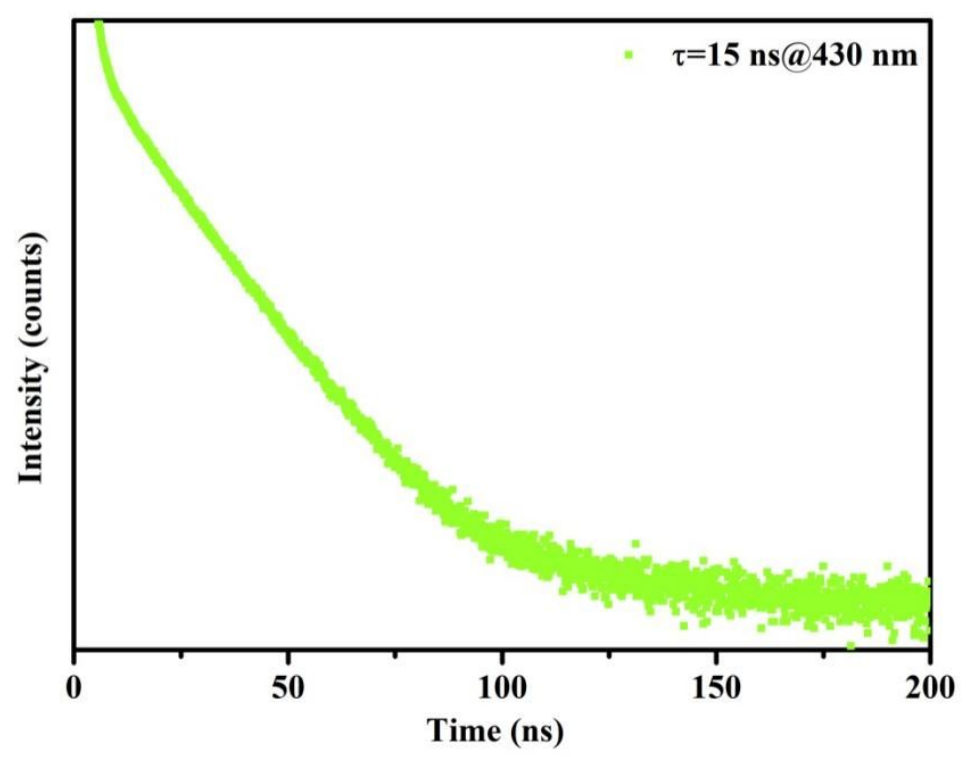

Figure S22. The lifetime of the fast decay at $430 \mathrm{~nm}$ of crystal sample 2. 


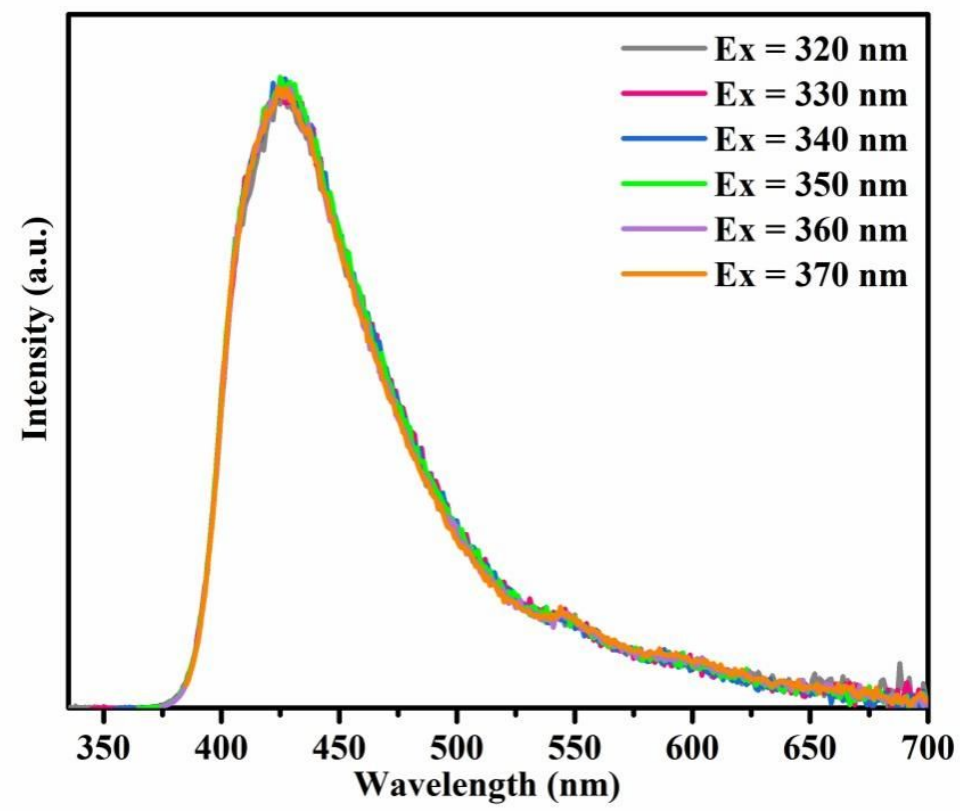

Figure S23. Changes of the fluorescence emission spectra upon different excitation wavelength of 1 at solid state.

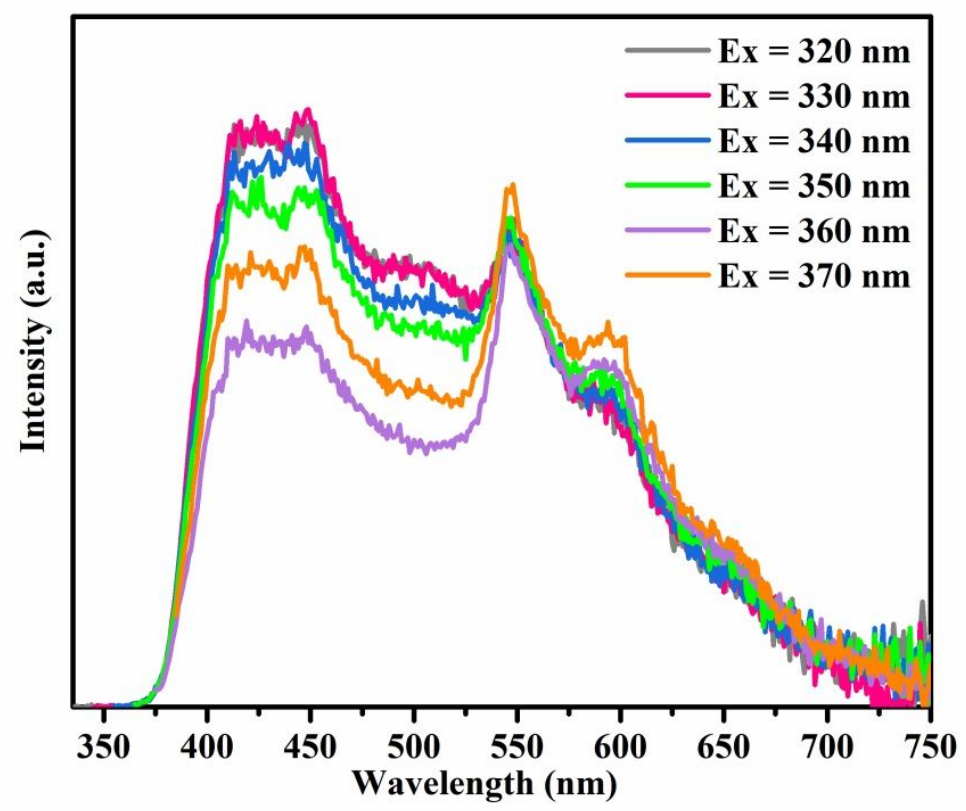

Figure S24. Changes of the phosphorescence emission spectra upon different excitation wavelength of 1 at solid state. It can be confirmed that the emission between $400-450 \mathrm{~nm}$ is fluorescence peaks, rather than phosphorescence. This is principally because the phosphorescence emission spectra was measured without the time-gated photomultiplier tube installation. 


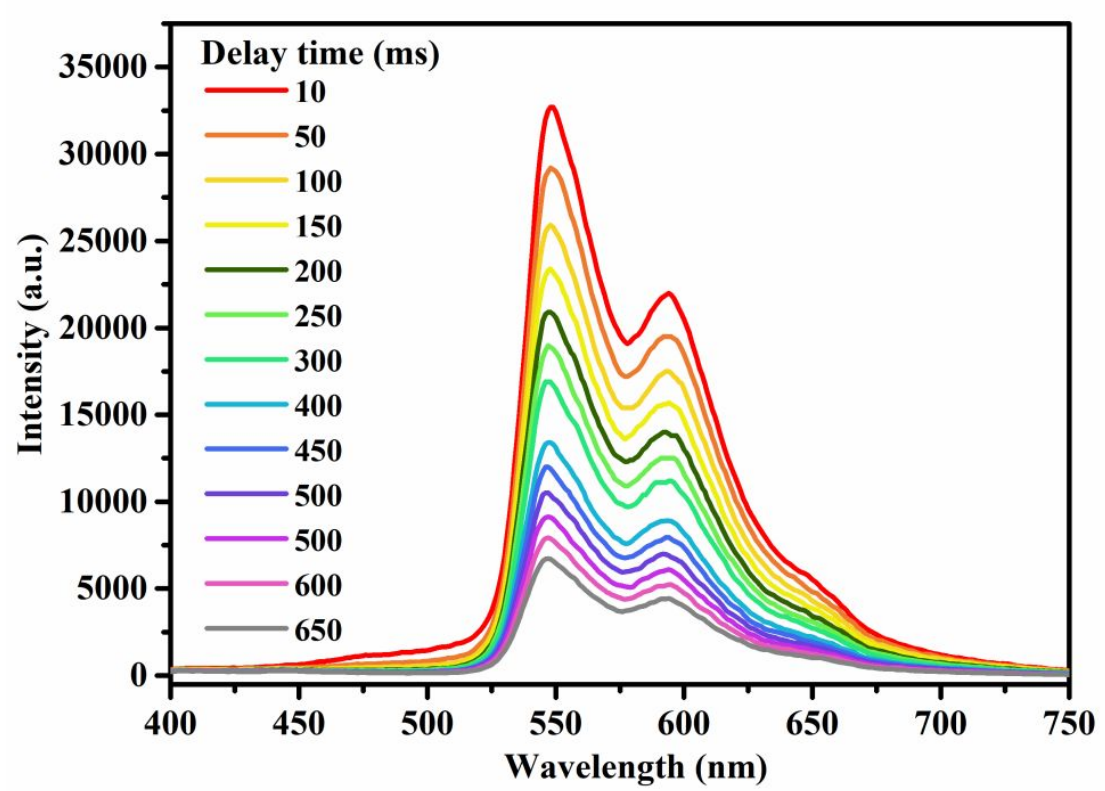

Figure S25. The phosphorescent spectra of compound 1 with different delayed time, the delayed time change from 10 to $650 \mathrm{~ms}$.

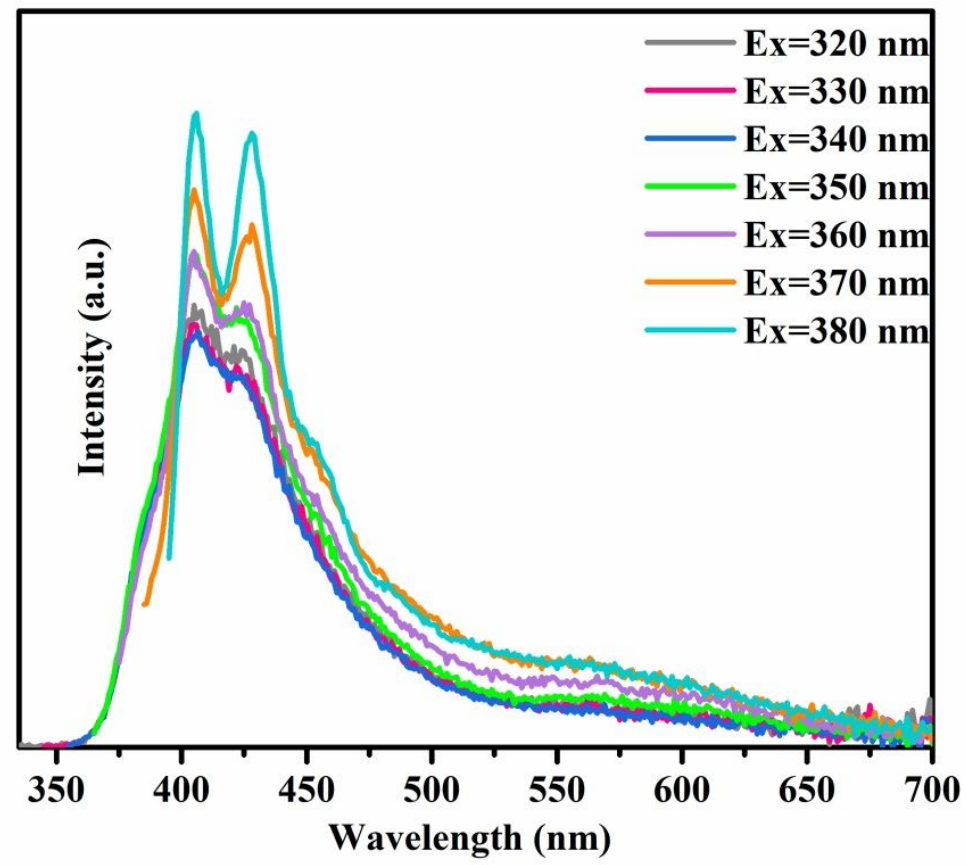

Figure S26. Changes of the fluorescence emission spectra upon different excitation wavelength of 2 at solid state. 


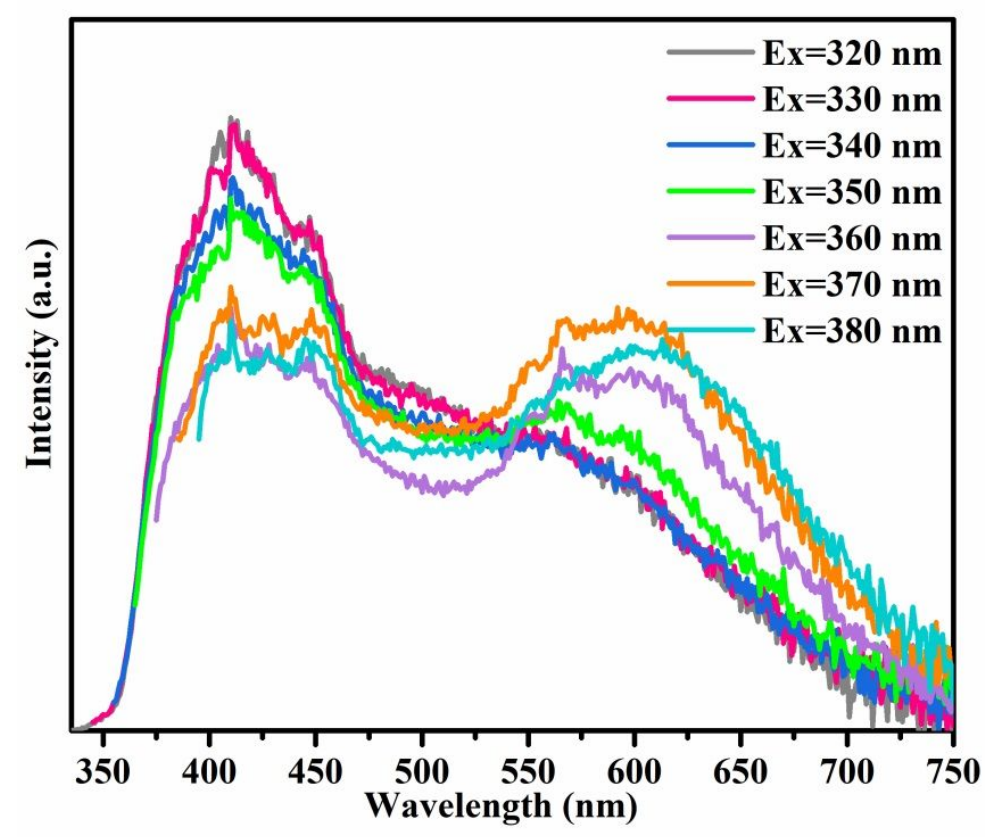

Figure S27. Changes of the phosphorescence emission spectra upon different excitation wavelength of 2 at solid state. It can be confirmed that the emission between $400-450 \mathrm{~nm}$ is fluorescence peaks, rather than phosphorescence. This is principally because the phosphorescence emission spectra was measured without the time-gated photomultiplier tube installation.

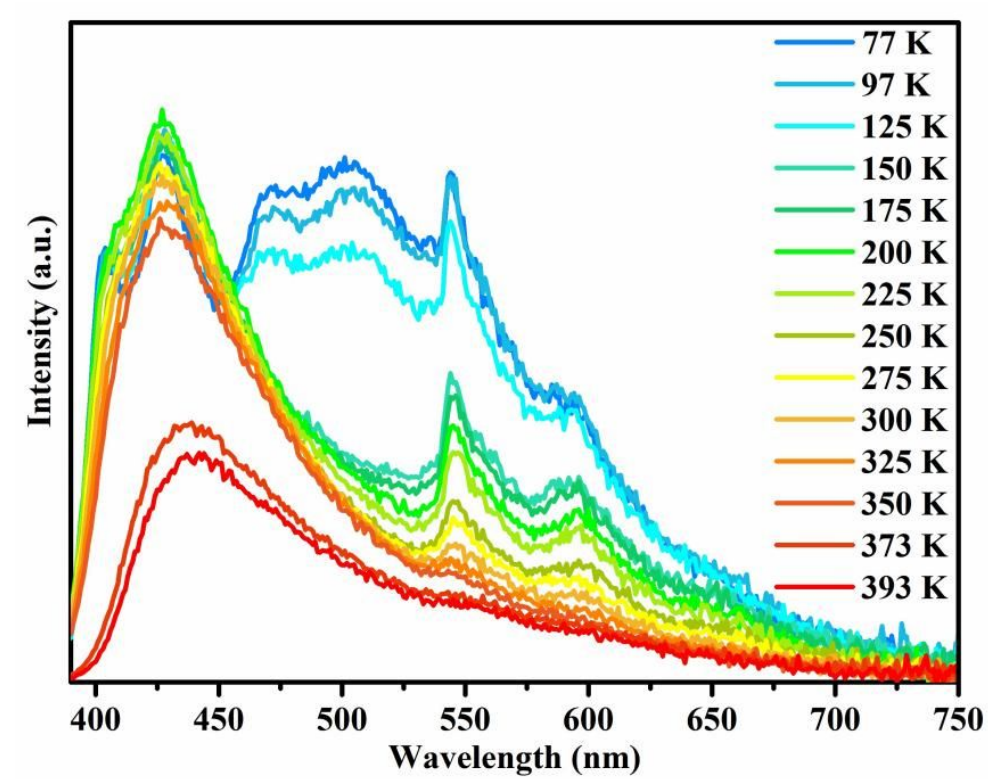

Figure S28. Changes of the emission spectra upon different temperature of $\mathbf{1}$ at solid state without gate operation. 


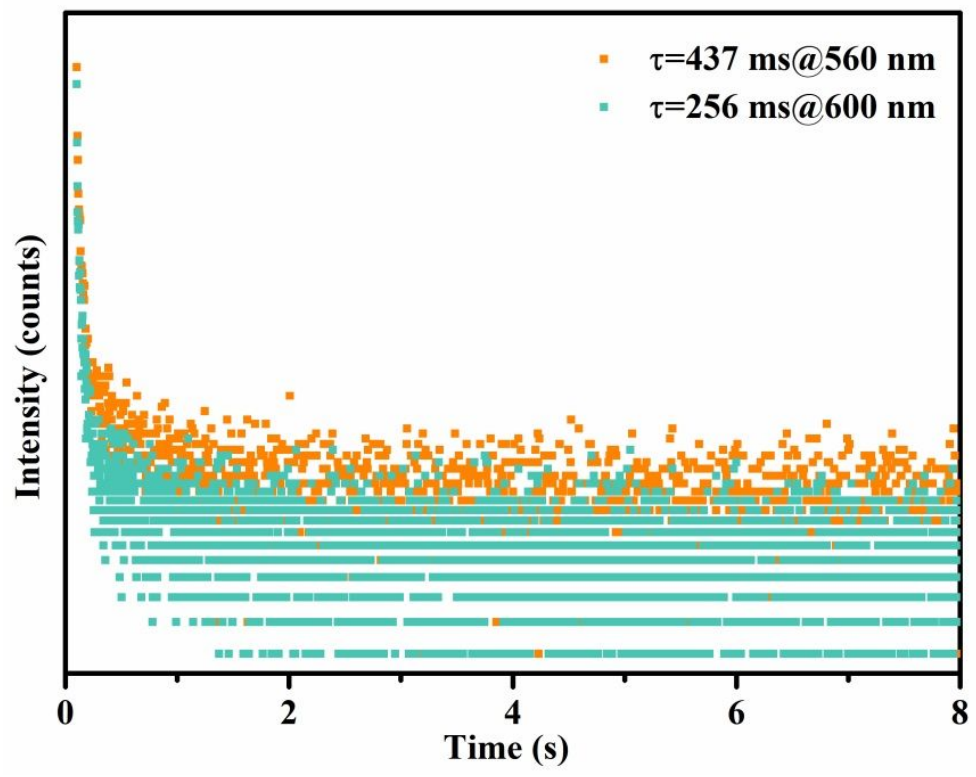

Figure S29. The RTP decay curves of compound 2.

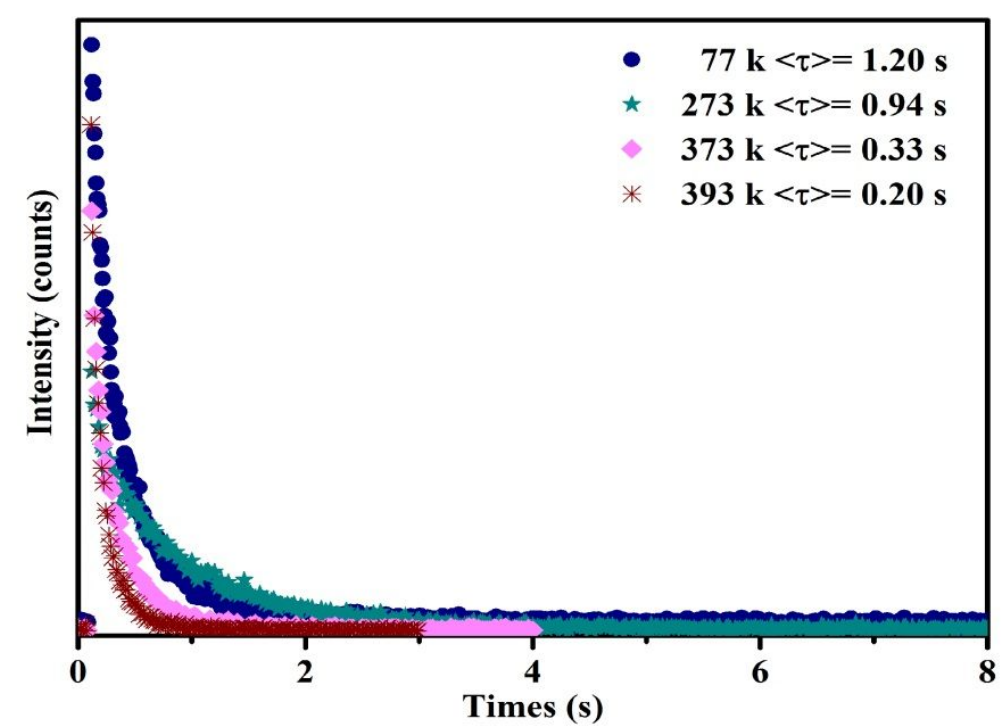

Figure S30. Temperature-dependent lifetime spectra of the $550 \mathrm{~nm}$ emission band of the crystal sample 1. 


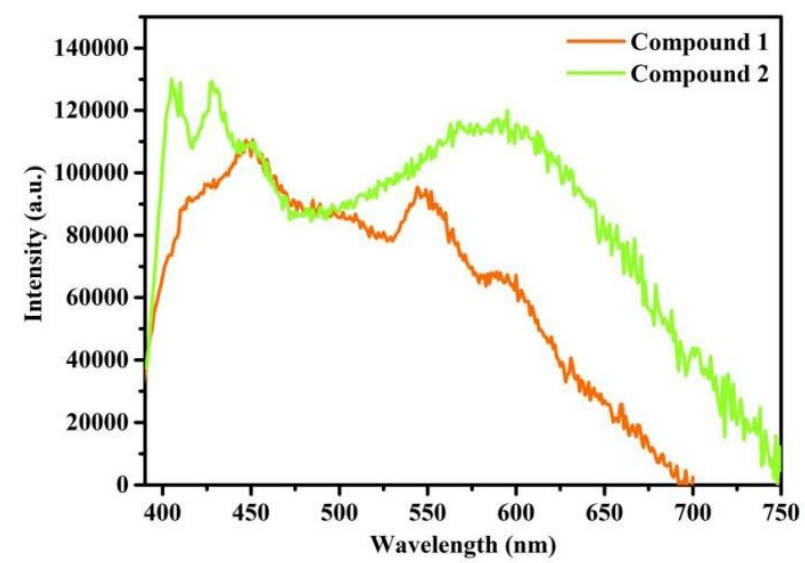

Figure S31. Prompt emission spectra of compounds $\mathbf{1}$ and $\mathbf{2}$ at room temperature.

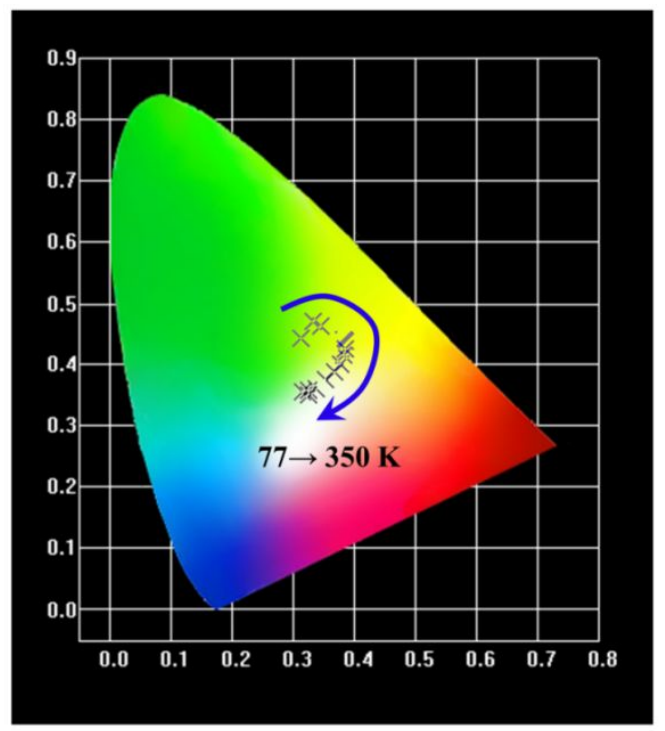

Figure S32. CIE 1931 coordinates of temperature-dependent color of compound 1.

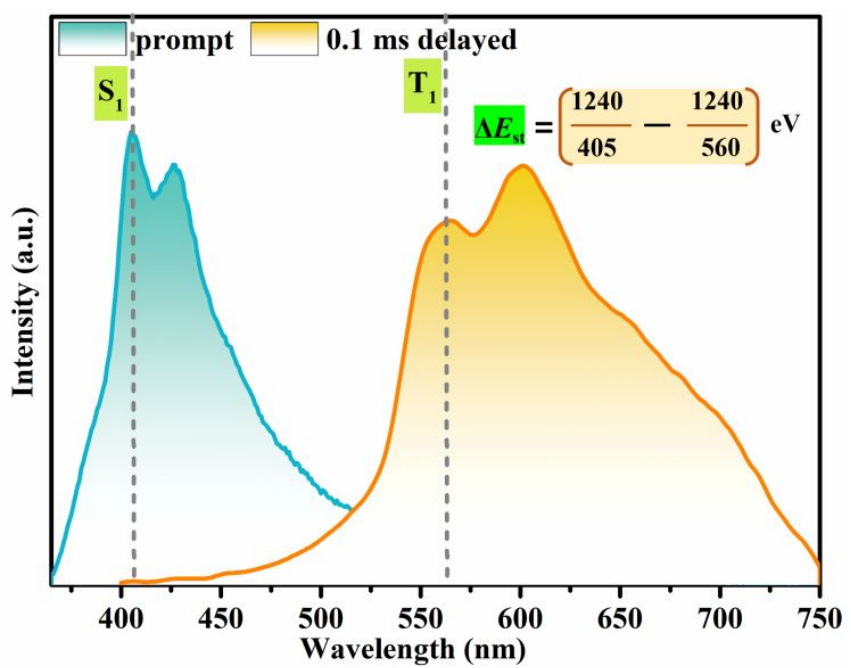

Figure S33 The steady-state photoluminescence spectrum (cyan line) and delayed photoluminescence spectrum (orange line) of compound 2 at $77 \mathrm{~K}$. The delayed photoluminescence spectra were collected with the delay time of $0.1 \mathrm{~ms}$. 


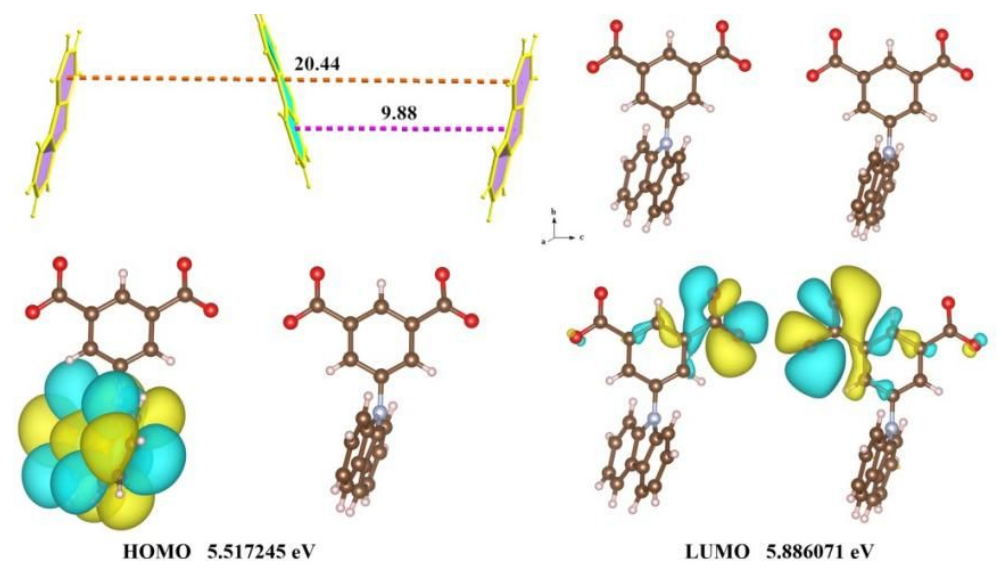

Figure S34. Calculated orbital energy level and involved frontier molecular orbitals of HOMO and LUMO for the corresponding monomer extracted from compound $\mathbf{2}$ crystals.

光源光谱测试报告
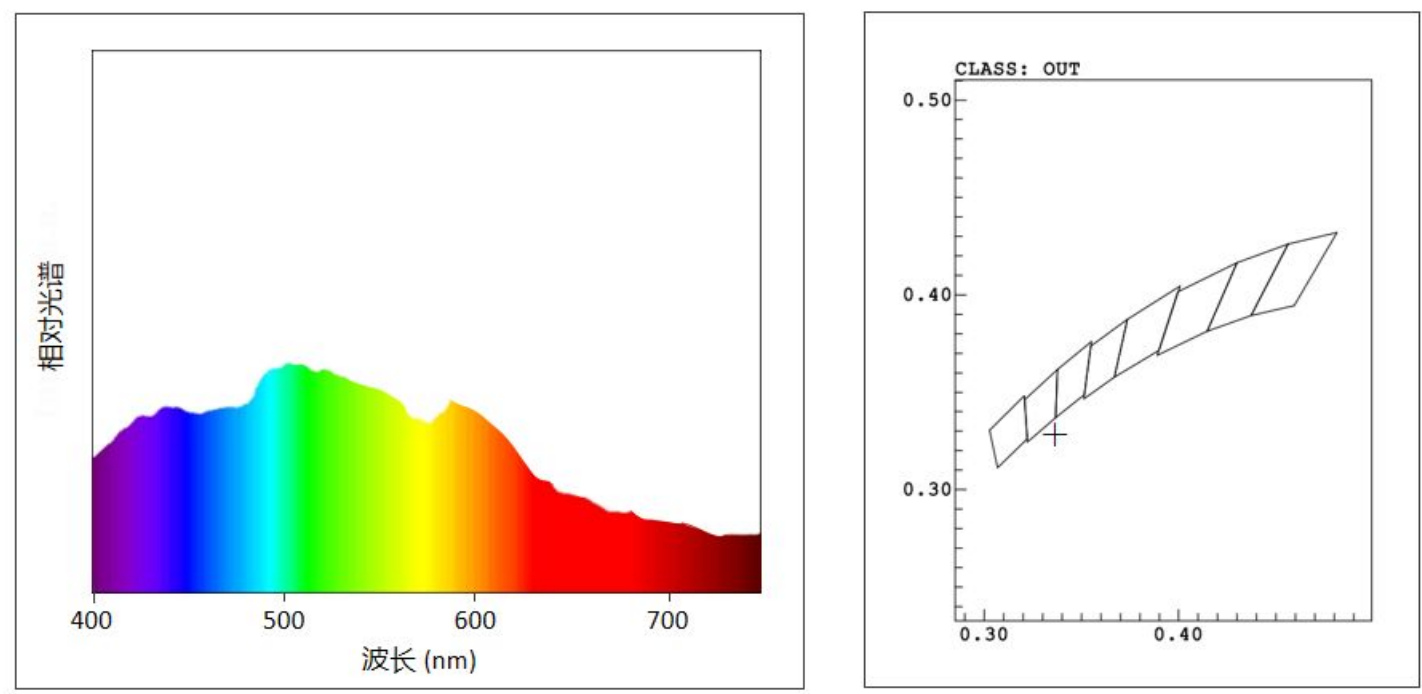

Figure S35 The luminescence spectra of WLED devices and the corresponding photo-to-electric parameters. 
Table S2. Crystallographic data of compound $\mathbf{1}$ and $\mathbf{2}$.

\begin{tabular}{|c|c|c|}
\hline Identification code & 1 & 2 \\
\hline Empirical formula & $\mathrm{C}_{70} \mathrm{H}_{61} \mathrm{~N}_{5} \mathrm{O}_{17} \mathrm{Cd}_{3}$ & $\mathrm{C}_{51} \mathrm{H}_{46} \mathrm{~N}_{6} \mathrm{O}_{11} \mathrm{Cd}_{2}$ \\
\hline Number of CCDC & 2070321 & 2070322 \\
\hline Formula weight & 1581.43 & 1143.74 \\
\hline Temperature/K & $293(2)$ & 293(2) \\
\hline Crystal system & monoclinic & monoclinic \\
\hline Space group & $P 2_{1} / \mathrm{c}$ & $P 2_{1} / \mathrm{c}$ \\
\hline $\mathrm{a} / \AA$ & $10.2368(2)$ & $14.4356(3)$ \\
\hline $\mathrm{b} / \AA$ & $15.6829(4)$ & $18.0148(3)$ \\
\hline $\mathrm{c} / \AA$ & $39.8412(8)$ & $20.4414(3)$ \\
\hline$\alpha /{ }^{\circ}$ & 90 & 90 \\
\hline$\beta /{ }^{\circ}$ & $91.588(2)$ & $103.4639(18)$ \\
\hline$\gamma / \circ$ & 90 & 90 \\
\hline Volume/ $\AA^{3}$ & $6393.8(2)$ & $5169.79(15)$ \\
\hline $\mathrm{Z}$ & 4 & 4 \\
\hline$\rho_{\text {calc }} \mathrm{g} / \mathrm{cm}^{3}$ & 1.643 & 1.469 \\
\hline$\mu / \mathrm{mm}^{-1}$ & 1.066 & 7.118 \\
\hline $\mathrm{F}(000)$ & 3184 & 2312 \\
\hline Crystal size/ $\mathrm{mm}^{3}$ & $0.17 \times 0.11 \times 0.10$ & $0.16 \times 0.12 \times 0.11$ \\
\hline Radiation & $\operatorname{MoK} \alpha(\lambda=0.71073)$ & $\operatorname{MoK} \alpha(\lambda=0.71073)$ \\
\hline $2 \theta$ range for data collection $/^{\circ}$ & 6.546 to 56.95 & 5.0670 to 73.8990 \\
\hline Index ranges & $\begin{array}{l}-13 \leq \mathrm{h} \leq 13,-21 \leq \mathrm{k} \leq 19, \\
\leq 1 \leq 53\end{array}$ & $\begin{aligned} 3-17 & \leq \mathrm{h} \leq 17,-21 \leq \mathrm{k} \leq 22 \\
-25 & \leq 1 \leq 24\end{aligned}$ \\
\hline Reflections collected & 91799 & 30639 \\
\hline Independent reflections & $\begin{array}{l}16172\left[\mathrm{R}_{\text {int }}=0.1177, \mathrm{R}_{\text {sigm }}\right. \\
0.0880]\end{array}$ & $\begin{array}{l}=10560\left[\mathrm{R}_{\text {int }}=0.0967, \mathrm{R}_{\text {sigma }}\right. \\
=0.0763]\end{array}$ \\
\hline Goodness-of-fit on $\mathrm{F}^{2}$ & 1.117 & 0.998 \\
\hline $\mathrm{R}_{1}^{\mathrm{a}}[\mathrm{I}>2 \sigma(\mathrm{I})]$ & $\mathrm{R}_{1}=0.1048, w \mathrm{R}_{2}=0.2403$ & $\mathrm{R}_{1}=0.0699, w \mathrm{R}_{2}=0.2002$ \\
\hline$w \mathrm{R}_{2}^{\mathrm{b}}$ (all data) & $\mathrm{R}_{1}=0.1373, w \mathrm{R}_{2}=0.2567$ & $\mathrm{R}_{1}=0.0756, w \mathrm{R}_{2}=0.2097$ \\
\hline $\begin{array}{l}\mathrm{a} \mathrm{R}_{1}=\left(\sum|| \mathrm{Fo}|-| \mathrm{Fc} \|\right) /\left(\sum|\mathrm{Fo}|\right) \cdot \mathrm{b} \\
w=1 /\left[\backslash \mathrm{s}^{\wedge} 2^{\wedge}\left(\mathrm{Fo}^{\wedge} 2^{\wedge}\right)+(0.0893 \mathrm{P})\right. \\
w=1 /\left[\backslash \mathrm{s}^{\wedge} 2^{\wedge}\left(\mathrm{Fo}^{\wedge} 2^{\wedge}\right)+(0.1640 \mathrm{P})\right.\end{array}$ & $\begin{array}{l}\mathrm{R} 2=\left[\sum \mathrm{w}\left(\mathrm{Fo}^{2}-\mathrm{Fc}^{2}\right)^{2} / \sum \mathrm{wFo}^{4}\right. \\
\wedge+8.9755 \mathrm{P}] \text { where } \mathrm{P}=\left(\mathrm{Fo}^{\wedge} 2^{\wedge}\right. \\
\wedge \text { where } \mathrm{P}=\left(\mathrm{Fo}^{\wedge} 2^{\wedge}+2 \mathrm{Fc}^{\wedge} 2^{\wedge}\right)\end{array}$ & $\begin{array}{l}2 \\
\left.2 \mathrm{Fc}^{\wedge} 2^{\wedge}\right) / 3 \text { for } 1 \\
\text { for } 2\end{array}$ \\
\hline
\end{tabular}




\section{REFERENCES}

1. L. M. Lifshits, D. S. Budkina, V. Singh, S. M. Matveev, A. N. Tarnovsky and J. K. Klosterman, Phys. Chem. Chem. Phys., 2016, 18, 27671-27683.

2. C. Chen, Z. Chi, K. C. Chong, A. S. Batsanov, Z. Yang, Z. Mao, Z. Yang and B. Liu, Nat. Mater. 2021, 20, 175-180.

3. Z. He, W. Zhao, J. W. Y. Lam, Q. Peng, H. Ma, G. Liang, Z. Shuai, B. Z. Tang, Nat. Commun., $\quad 2017, \mathbf{8}, 416$.

4. T. Zhang, H. Gao, A. Lv, Z. Wang, Y. Gong, D. Ding, H. Ma, Y. Zhang and W. Z. Yuan, J. Mater. Chem. C, 2019, 7, 9095-9101. 